\title{
Coadministration of Nematophagous Fungi for Biological Control over Nematodes in Bovine in the South-Eastern Brazil
}

\author{
Fábio Dias Luns, ${ }^{1}$ Rafaela Carolina Lopes Assis ${ }^{D},{ }^{1}$ Laryssa Pinheiro Costa Silva, ${ }^{2}$ \\ Carolina Magri Ferraz, ${ }^{2}$ Fábio Ribeiro Braga, ${ }^{2}$ and Jackson Victor de Araújo ${ }^{1}$ \\ ${ }^{1}$ Department of Veterinary Medicine, Laboratory of Parasitology, Federal University of Viçosa, Av. P.H. Rolphs, \\ Viçosa Campus, 36570-000 Viçosa, MG, Brazil \\ ${ }^{2}$ Department of Veterinary Medicine, University Vila Velha, Avenue Comissário José Dantas de Melo, 21, \\ Boa Vista, 29102-920 Vila Velha, ES, Brazil \\ Correspondence should be addressed to Rafaela Carolina Lopes Assis; rafaelalopesassis@yahoo.com.br
}

Received 13 October 2017; Revised 19 January 2018; Accepted 20 February 2018; Published 26 March 2018

Academic Editor: Juan F. J. Torres-Acosta

Copyright (C) 2018 Fábio Dias Luns et al. This is an open access article distributed under the Creative Commons Attribution License, which permits unrestricted use, distribution, and reproduction in any medium, provided the original work is properly cited.

\begin{abstract}
This study compared the coadministration among the three nematode predatory fungi, Duddingtonia flagrans, Monacrosporium thaumasium, and Arthrobotrys robusta, in the biological control of cattle gastrointestinal nematodiasis in comparison with the use of the fungus D. flagrans alone. Five groups consisting of eight Girolando heifers were kept in paddocks of Brachiaria decumbens for six months. Each heifer received $1 \mathrm{~g} / 10 \mathrm{~kg}$ of pellets containing the fungi $(0.2 \mathrm{~g}$ of fungus $/ 10 \mathrm{~kg}$ b.w. $)$. Group 1 (G1) received pellets with $D$. flagrans and $M$. thaumasium in coadministration, G2 received D. flagrans and A. robusta, G3 received M. thaumasium, A. robusta, and D. flagrans, and G4 received the fungus D. flagrans alone. Group 5 (control) received pellets without fungi. The monthly mean of fecal egg count (FEC) of Groups 1, 2, 3, and 4 were 93.8, 85.3, 82.7, and 96.4\% smaller than the mean of control group. The treatments with pellets containing $D$. flagrans or $D$. flagrans $+M$. thaumasium produced significantly better results than the D. flagrans $+A$. robusta or the combination of the three fungi. The associations which include A. robusta were less efficient in this study than D. flagrans alone or associated with M. thaumasium.
\end{abstract}

\section{Introduction}

Nematode-trapping fungi are the most studied group of fungal nematode antagonists. They have the greatest potential for destroying infectious forms of gastrointestinal nematode parasites among both animals and humans $[1,2]$. The fungal species Duddingtonia flagrans, Monacrosporium thaumasium, and Arthrobotrys robusta were identified as predators of nematodes and they have been studied as biological control agents for these parasites [3-5]. Research on the application of the nematode-trapping fungi $D$. flagrans $[6,7]$, A. robusta $[5,8]$, and $M$. thaumasium $[9,10]$ in the treatment of gastrointestinal nematodiasis in bovines has demonstrated the potential of these fungi in reducing the free-living stages of parasitic nematodes (L3) in the field. The use of more than one biocontrol agent is considered a primary suppressive measure that contributes to controlling the presence of infectious agents in soil [11]. The use of a combination of several nematophagous fungi can minimize any potential flaws in their individual administration, or it may even enhance their actions as biocontrol agents [12]. Furthermore, numerous biological control mechanisms (including the production and use of substances that exert fungicidal effects) may vary among species and even among isolates of the same species, resulting in interactions between fungi that may interfere with their antagonistic performance [13]. However, most of the studies examining biological control in cattle have been conducted with fungal isolates applied alone. There are no reports of previous in vivo studies that have evaluated the biological control achieved following coadministration of $D$. flagrans, A. robusta, and $M$. thaumasium in extensive systems of dairy cattle. It is unclear whether the coadministration of a few of these species could yield additive effects from a biological standpoint [14]. Many studies have already proven the effectiveness of the fungus. D. flagrans in the biological control of nematodes of several 
species $[1-3,6,7]$. We then chose this fungus to compare the treatment groups with fungal association. In this context, the objective of this study was to evaluate the effects of the coadministration of nematode-trapping fungi $A$. robusta, $D$. flagrans, and $M$. thaumasium on gastrointestinal helminths in combination would be synergistic or antagonistic in nature compared to Duddingtonia flagrans used alone.

\section{Materials and Methods}

2.1. Area of Study. The experiment was carried out at a private farm located in the municipality of Ouro Branco, state of Minas Gerais, in the south-eastern region of Brazil, $20^{\circ} 31^{\prime} 15^{\prime \prime}$ south latitude and $43^{\circ} 41^{\prime} 31^{\prime \prime}$ west longitude, from April to September 2012. The paddock's topography is undulating to hilly (5\% flat, $60 \%$ undulating, and 35\% hilly), with an mean altitude of 1,052 m (maximum: 1,568 m; minimum: 1,099 m) and featuring native vegetation indicative of a transition zone between the Atlantic forest and savanna. The climate is tropical (Köppen-Geiger climate classification: Aw), with an annual mean maximum temperature of $22^{\circ} \mathrm{C}$ and a minimum temperature of $7^{\circ} \mathrm{C}$ and featuring an mean annual rainfall of $1,200 \mathrm{~mm}$.

2.2. Fungi and the Production of a Mycelial Mass. Isolates of three fungal species that are known predators of nematodes were used: A. robusta (I31), D. flagrans (AC001), and $M$. thaumasium (NF34). These isolates were obtained from soils in the Zona da Mata region of the state of Minas Gerais, Brazil. Mycelium was obtained by transferring disks ( $\sim \mathrm{mm}$ in diameter), which were cultured with the fungal isolates in $2 \%$ water agar (2\% WA), to Erlenmeyer flasks $(250 \mathrm{~mL}$ in capacity) containing $150 \mathrm{~mL}$ of liquid glucose-yeast-peptone (GYP) medium [3]. These flasks were then incubated in the dark, under agitation at $120 \mathrm{rpm}$, at $26^{\circ} \mathrm{C}$ for 10 days. Following this period, the fungal mycelium was removed and weighed on an analytical balance. All of the procedures followed the methodology of Araújo et al. [10].

2.3. Experimental Animals. At the beginning of the experiment, a total of 40 6-month-old Girolando heifers, with an mean body weight (b.w.) of $120 \mathrm{~kg}$, were pretreated with $10 \%$ albendazole (Mogivet $\mathrm{Lab}^{\circledR}$, Brazil), which was orally administered at a dose of $1 \mathrm{~mL} / 20 \mathrm{~kg}$ of b.w. Fifteen days after the antihelminthic treatment, the heifers were separated into one of five groups (Groups 1, 2, 3, 4, and 5) consisting of eight heifers each, based on the animals' mean weight.

The heifers were allocated in five paddocks of Brachiaria decumbens that had been previously grazed by young and adult animals and which were naturally infected with gastrointestinal helminth parasites. Each paddock had an area of 15 ha. Each group was allocated in only one paddock without rotational grazing during the experimental period. Each animal from all groups treated (G1, G2, G3, and G4) received $1 \mathrm{~g}$ of pellets $(0.2 \mathrm{~g}$ of fungal mycelium) per $10 \mathrm{~kg}$ of b.w. The animals from Group 5 received $1 \mathrm{~g}$ of fungus-free pellets per $10 \mathrm{~kg}$ of b.w. All of the animals received the pellets orally twice a week. The pellets were mixed in a concentrated and balanced ration provided for dairy cattle (accounting for $18 \%$ of the cattle's total protein, Federal University of Viçosa). The cattle were given water ad libitum for 6 months, starting from April 2012.

The differences between the groups were in the composition of the pellets. Pellets of group 1 (G1) contained the fungi $D$. flagrans and $M$. thaumasium, while the pellets of Group 2 (G2) contained the fungi D. flagrans and A. robusta. Group 3 (G3) received pellets containing the three fungi D. flagrans, A. robusta, and M. thaumasium. Group 4 (G4) pellets contained only the $D$. flagrans fungus. The pellet doses of the different groups were all comparable; with respect to the proportions of fungi species included in each pellet, Groups 1 and 2 contained $50 \%$ of each of two fungi, while the pellets combining the three fungal isolates (Group 3) were comprised of one-third of each fungus.

After allocating the heifers to the paddocks, the animals' fecal samples were collected directly from the rectum, once a week, to determine the number of nematode fecal egg count (FEC), as described by Gordon and Whitlock [15].

Meteorological data were recorded daily at a specialized station in the region; the mean of the maximum, mean, and minimum monthly temperatures, as well as the mean rainfall, were noted.

Fecal samples were collected to observe fungal growth once a week, 2 days after the animals were treated with the fungi. The feces were incubated in plates containing 2\% WA; 100 L3 were recovered from the coproculture and they were placed into a drying oven at $25^{\circ} \mathrm{C}$ for 10 days to confirm the passage and predatory ability of the fungi through the cattle's gastrointestinal tract, as well as to assess fungal growth in the feces [3].

Coproculture was evaluated together with FEC counts; $20 \mathrm{~g}$ of feces was mixed with autoclaved wood shavings and kept moist at a controlled temperature $\left(25^{\circ} \mathrm{C}\right)$ for 7 days to obtain trichostrongylid larvae. Identification of the infective larvae in the coproculture was performed according to Keith [16].

The FEC and larvae recovered from the coproculture of animals in both the treated and control groups were recorded, and the percentage of larval reduction was determined according to De Gives et al. [17]: reduction (\%) = mean L3 recovered from control group - mean L3 recovered from treated group $\times 100 /$ mean L3 recovered from the control group.

The FEC, number of infective larvae recovered from the feces, were statistically analyzed on a weekly basis and compared over the experimental period.

The data were transformed into $\log (x+1)$ prior to the analysis and subjected to analysis of variance (ANOVA) with repeated measures, Tukey's test, and regressions using a randomized design at probability levels of $1 \%$ and $5 \%$.

The animals' weights were also compared throughout the experiment, starting from April 2012. The correlation analyses were performed using Pearson's correlation $(P<$ 0.001). The analyses were performed using the BioEstat 3.0 Software.

The Ethics Committee of the Federal University of Viçosa protocol number 66/2012 approved this study. 


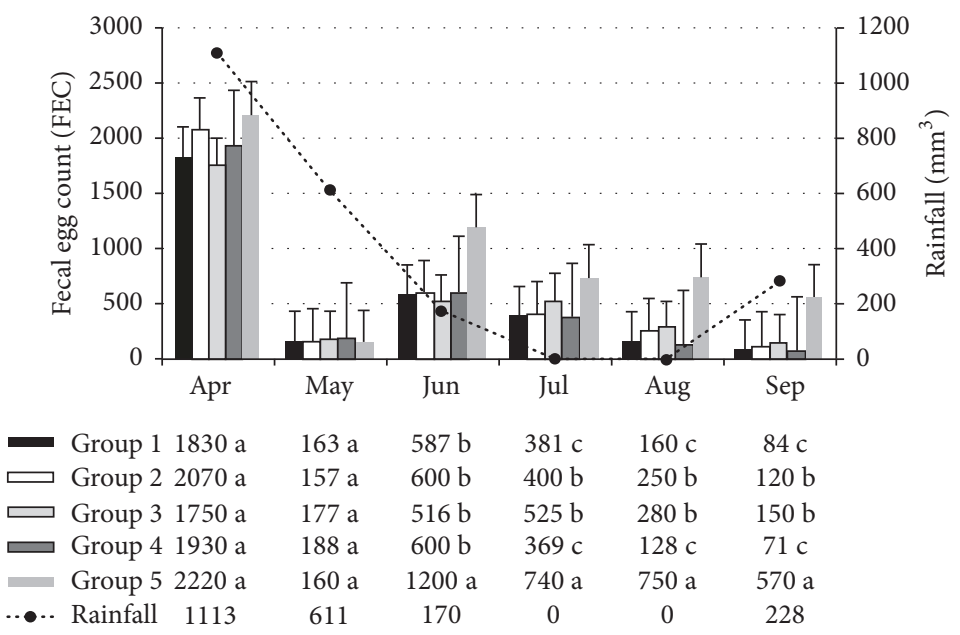

FIGURE 1: Monthly mean of the fecal eggs count (FEC) among heifers in the groups treated with various combinations of coadministered nematophagous fungi: D. flagrans + M. thaumasium (G1); D. flagrans + A. robusta (G2); D. flagrans + M. thaumasium + A. robusta (G3); D. flagrans alone (G4); and the control group. All samples were collected from April to September 2012 in Ouro Branco, MG, Brazil. (a,b,c Numbers followed by different letters present statistical difference.)

\section{Results}

The monthly mean values of FEC counts are shown in Figure 1. In the first month of the experiment, no statistically significant differences were found $(P>0.05)$ between the groups treated with fungi (G1, G2, G3, and G4) and the control group (group 5). In the first month of treatment (May 2012), the low FEC number was likely due to the previously administered anthelmintic treatment. The FEC of animals treated with $D$. flagrans and $M$. thaumasium (Group 1); $D$. flagrans and A. robusta (Group 2); D. flagrans, A. robusta, and $M$. thaumasium (Group 3); and D. flagrans (Group 4), that is, all treated groups, were significantly lower than those of the control group from June to September $2012(P<0.05)$. However, the FEC of the animals treated with $D$. flagrans and $M$. thaumasium (Group 1) and with D. flagrans alone (Group 4) were significantly lower than those treated with $D$. flagrans and A. robusta (Group 2) and with D. flagrans, A. robusta, and M. thaumasium (Group 3) $(P<0.05)$ (Figure 1).

The monthly mean FEC of the animals in the group treated with pellets containing the fungus $D$. flagrans alone, as well as those treated with pellets containing both $D$. flagrans and M. thaumasium, were $96.4 \%$ and $93.8 \%$ lower, respectively, than the FEC of the animals in the control group at the end of the experiment. The animals from Group 2 , which were treated with pellets containing the fungi $D$. flagrans and A. robusta, as well as the animals from Group 3 (treated with pellets containing the three fungi), exhibited FEC reductions of $85.3 \%$ and $82.7 \%$, respectively, when compared with the animals in the control group. Moreover, the FEC counts were significantly lower in Groups 1 and 4 when compared with Groups 2 and 3 at the end of the experiment $(P<0.05)$.

Figure 2 shows the maximum, mean, and minimum temperatures, as well as the mean monthly rainfall. Overall, it was found that the meteorological data correlated with

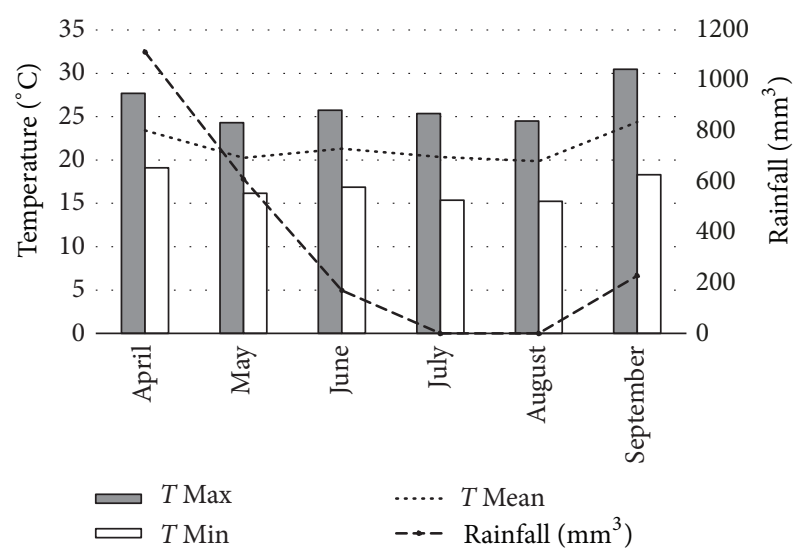

FIGURE 2: The mean of the maximum, mean, and minimum monthly temperatures $\left({ }^{\circ} \mathrm{C}\right)$ and monthly rainfalls $\left(\mathrm{mm}^{3}\right)$ recorded from April to September 2012, Ouro Branco, MG, Brazil.

the parasitological findings, as temperatures and rainfall influenced the environmental parasite load.

The coproculture showed that the Cooperia sp. was the most prevalent gastrointestinal parasitic nematode in all groups throughout the experiment, which was observed at percentages of $68 \%, 67.6 \%, 60.6 \%, 46.2 \%$, and $45.1 \%$ for Groups 1, 2, 3, 4, and 5, respectively; this was followed by Haemonchus, which was found at rates of $22.8 \%, 24.8 \%$, $30.4 \%, 45.5 \%$, and $45.8 \%$, and Oesophagostomum, which was observed at rates of $9.2 \%, 8.4 \%, 8.4 \%, 9.2 \%$, and $8.7 \%$, respectively. No significant differences $(P>0.01)$ were found with respect to the proportion of the different genera among the five groups. The percent reduction of L3 recovered from each coproculture of the treated groups was significantly lower when compared with that of the control group. The reductions were $92.3 \%, 90.7 \%, 81.5 \%$, and $78.3 \%$ for Groups $1,2,3$, and 4 , respectively. 


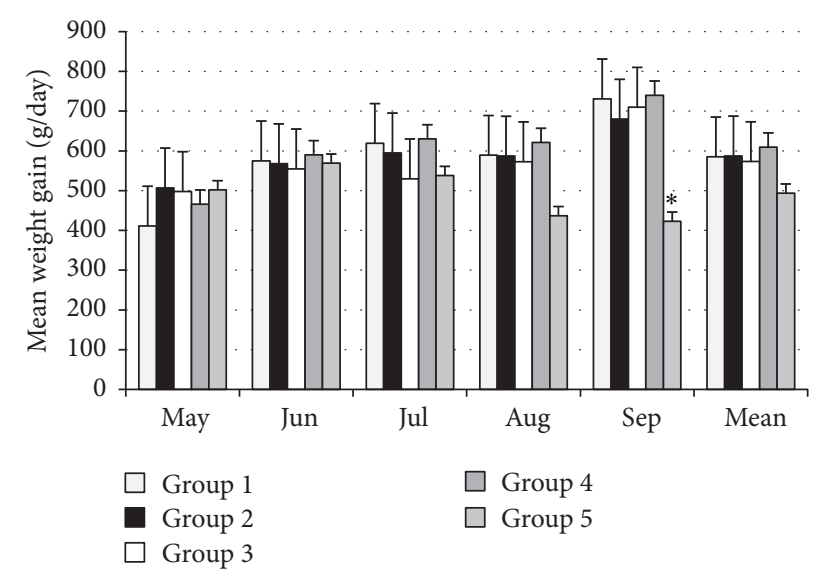

FIGURE 3: Mean weight gains (g/day) from each group. Measurements were taken from April to September 2012 in Ouro Branco, MG, Brazil. Significant differences between each treated group and the control group are indicated by an asterisk (Tukey's test).

Analysis of the culture plates confirmed the fungal growth, the specific conidia of each isolate, and the ability of D. flagrans, A. robusta, and M. thaumasium to predate L3 in all treated groups, confirming the passage of the isolates through the animals' gastrointestinal tracts. The presence of nematophagous fungi was not detected in the feces of the control group animals during the experiment.

Figure 3 shows the mean weight gains for the animals in the five groups. The weight gains of the animals in the treated groups (G1, G2, G3, and G4) differed from those of the animals in the control group $(\mathrm{G})(P<0.05)$ in the last month of the study.

\section{Discussion}

Studies evaluating the coadministration of nematophagous fungi are scarce, and this work was the first to evaluate the combined use of the fungi $A$. robusta, D. flagrans, and M. thaumasium in bovines. In this study, the heifers from the group treated with $D$. flagrans alone exhibited an FEC reduction of $96.4 \%$ when compared with the heifers in the control group. Several studies using the fungus $D$. flagrans in ruminants also reported smaller monthly mean FEC counts among the treated animals in relation to the control group $[3,18-20]$. In studies using the same D. flagrans isolate, in Brazil, others researchers also obtained significant reductions in FEC in treated crossbred Holstein-Zebu and Nellore bulls, $31 \%$ and $57 \%$.

There was a $93.8 \%$ reduction in the FEC among the group treated with $D$. flagrans and $M$. thaumasium when compared with the FEC of the control group. Studies using $M$. thaumasium in bovines reported that the monthly mean FEC were lower in treated animals. In studies where crossbred Holstein-Zebu heifers and Nellore bulls were treated with this same Monacrosporium thaumasium isolate, the authors obtained FEC reductions of $88.8 \%$ and $47.8 \%$, respectively $[3,9]$.
Furthermore, the coadministration of pellets containing $D$. flagrans and M. thaumasium employing the same formulation as that used in this experiment was tested in sheep and the author demonstrated that this treatment was effective in controlling gastrointestinal helminths in young and adult sheep in the semiarid region of northeastern Brazil [21]. In addition, the researchers found that the FEC rates remained statistically significantly lower throughout the study without the administration of salvage deworming, reaching a $76 \%$ reduction in the FEC of treated animals when compared with the FEC of controls, which still required to be dewormed seven times [21].

In this study, the group treated with $D$. flagrans and $A$. robusta showed an FEC reduction of $85.3 \%$ in relation to that of the control group. Other study reported a 51.9\% reduction in the FEC of crossbred Holstein-Zebu calves treated with an isolate of $A$. robusta.

Moreover, the compatibility between isolates A. robusta and $D$. flagrans was evaluated under laboratory conditions. With the aid of direct confrontation and antibiosis and volatile metabolite tests, the authors verified that the $A$. robusta isolate colonized approximately two-thirds of the plate, suggesting that there was competition (and subsequent antagonism) between these two fungi. Specifically, A. robusta reduced the growth of $D$. flagrans, suggesting the action of volatile antibiotics in inhibiting mycelial growth. These results corroborate the findings of the in vivo experiment described herein, since the groups of animals that received the coadministration treatments containing the A. robusta isolate demonstrated lower nematode reduction results when compared to the other treatments with statistical significance $(P<0.05)$.

The heifers in the group treated with the combination of the three fungi had an FEC reduction of $82.7 \%$ when compared with the animals in the control group. There are no previous records in the literature describing the coadministration of the three nematophagous fungi in the biological control of nematode parasites in vivo. This is the first report of its kind; the fungal combinations that were tested were effective in reducing the FEC in cattle. Furthermore, the coadministration of these three isolates was less effective than the coadministration of $D$. flagrans and M. thaumasium, or the administration of the $D$. flagrans isolate alone, at reducing the FEC.

Trap formation and L3 predation by fungal isolates were confirmed by in vitro assays. Braga et al. [1] reported that $D$. flagrans showed greater predatory activity in vitro (80.3\%) on L1 Angiostrongylus vasorum when compared with $M$. thaumasium (74.5\%) and A. robusta (71.8\%). In another in vitro study, Braga et al. [22] compared the predatory ability of the same isolates used in this study on L3 Strongyloides stercoralis. The L3 reductions were $83.7 \%$ (D. flagrans), $75.5 \%$ (M. thaumasium), and $73.2 \%$ (A. robusta). A study conducted to examine the interaction between $\mathrm{L} 3 \mathrm{H}$. contortus in goat and the fungi $M$. thaumasium and $A$. conoides showed that both strains were able to reduce the larval population, but $M$. thaumasium proved to be more efficient [23]. These results are in agreement with the findings of this work; the greatest reduction in L3 observed at the end of the experiment was 
due to D. flagrans, while combinations featuring A. robusta were less efficient at reducing L3 and the FEC counts.

In the present study, the percent reduction of $\mathrm{L} 3$ achieved by the $M$. thaumasium isolate alone was $92.3 \%$. Similarly, Araújo et al. [10] recorded larval reduction in the coproculture of animals treated with $M$. thaumasium in the Brazilian semiarid region. In their study, the combination of $D$. flagrans and $M$. thaumasium resulted in a $90.7 \%$ decrease in the number of larvae in the coproculture.

Furthermore, the in vitro action of fungal isolates $A$. robusta and $M$. thaumasium on L3 cyathostome in horses was compared and the percent reduction obtained with $M$. thaumasium 313 (93.4\%) was higher than that obtained with the $A$. robusta isolate $(86.3 \%)$ at $25^{\circ} \mathrm{C}$. The combination of the same isolates (A. robusta $+M$. thaumasium) in this study reduced the $\mathrm{L} 3$ recovered in the coproculture by $81.5 \%$, while a combination of isolates $A$. robusta $+M$. thaumasium + the fungus $D$. flagrans decreased L3 by $78.3 \%$.

It is important to note that climate plays an important role in the ability of fungi to trap nematodes, particularly since the optimum growth temperature varies with each fungal species. Morgan et al. observed that temperatures in the range of $20^{\circ} \mathrm{C}-33^{\circ} \mathrm{C}$ influenced the larvae trapping percentage in different species of fungi [24]. Thus, optimal rainfalls and predation temperatures, that is, specific environmental climatic conditions, may be directly related to the results of this study. To support this, Castro et al. reported that $A$. robusta exhibited the best larval trapping results at temperatures ranging from $25^{\circ} \mathrm{C}$ to $28^{\circ} \mathrm{C}$, while $M$. thaumasium was not affected by temperatures of $25^{\circ} \mathrm{C}-30^{\circ} \mathrm{C}$, which confirms that temperature influences the degree of trapping, depending on the cyathostome species or genus [25].

In addition, Castro et al. obtained a $93.36 \%$ reduction in the number of cyathostome larvae after administering $M$. thaumasium at $25^{\circ} \mathrm{C}$. The authors found that temperatures of $25^{\circ} \mathrm{C}, 28^{\circ} \mathrm{C}$, and $30^{\circ} \mathrm{C}$ did not affect the performance of $M$. thaumasium, which demonstrated an mean efficiency of $94 \%$ [25]. The results obtained in our study corroborate the findings of these previous works and suggest that the efficiency with which larvae are controlled by nematophagous fungi essentially depends on the choice of the fungal species, as well as on their suitability for specific temperature conditions.

The fungus Monacrosporium demonstrated unvarying performance in vitro at a temperature range of $15^{\circ} \mathrm{C}-30^{\circ} \mathrm{C}$, as reported by Mendoza-de Gives and Vázquez-Prats [26] and Castro et al. [25] even at $30^{\circ} \mathrm{C}$, a common temperature in the tropics; thus this fungi would be better adapted to the conditions of the Brazilian climate. These results may support and explain the higher degree of efficiency exhibited by the combination $M$. thaumasium and $D$. flagrans in reducing the FEC and L3 in this study, particularly when compared with the administration of $A$. robusta and D. flagrans. Moreover, the results also corroborate the reduced percentage of L3 observed in the coproculture after administering combinations featuring $A$. robusta. In this study, the region's temperatures ranged from $24.3^{\circ} \mathrm{C}$ to $30.5^{\circ} \mathrm{C}$, which may be considered unsuitable for optimal predation by $A$. robusta.

Of note, all of the treated groups showed a similar pattern of weight gain during the study. Even though notable weight gain differences were found between heifers in the treated groups, there was a significant difference $(P<0.01)$ in weight gain between the treated groups, which varied in an inversely proportional manner to both the number of larvae recovered in pasture and the FEC. Specifically, the heifers treated with $D$. flagrans and D. flagrans $+M$. thaumasium showed greater mean weights. This reinforces the fact that administering pellets containing fungi was favored when the animals were pretreated. Moreover, greater weight gains in the treated animals (as compared to those in the control group) were also observed by Araújo et al. when testing the fungus $M$. thaumasium in goats in the Brazilian semiarid region. Furthermore, Braga et al. [1] studied horses in the field; the researchers administered the nematophagous fungus $D$. flagrans, and they observed significant weight gain differences between the groups treated with the fungus and the control animals. The animals that were treated with the fungus demonstrated greater weight gains than those in the control group.

\section{Conclusion}

Treating dairy cattle with alginate pellets containing, and coadministering, the nematophagous fungi D. flagrans, $A$. robusta, and $M$. thaumasium resulted in the biological control of gastrointestinal nematodes in bovines, although the level of control was not increased when compared with the use of the fungus $D$. flagrans alone. Coadministration with the A. robusta isolate was not considered a good alternative. The administration of $D$. flagrans alone was found to be more promising than coadministration for continuous use in dairy cattle in this tropical region in Brazil.

\section{Ethical Approval}

The authors assert that all procedures contributing to this work comply with the ethical standards of the relevant national and institutional committees on human experimentation and with the Helsinki Declaration of 1975, as revised in 2008.

\section{Conflicts of Interest}

The authors declare that they have no conflicts of interest.

\section{Acknowledgments}

The authors would like to thank the author of the thesis "Viability of Predatory Fungi M. 421 thaumasium and D. flagrans and Moxidectin on Gastrointestinal Nematodes of Beef 422 Cattle," a member of this research group, whose methodology forms the basis of this paper 423 and they acknowledge Fundação de Amparo à Pesquisa de Minas Gerais (FAPEMIG) for the support in 424 project financing and in scientific dissemination for the publication of this paper. This work was financially supported by FAPEMIG and CAPES. 


\section{References}

[1] F. R. Braga, J. V. Araújo, A. R. Silva et al., "Biological control of horse cyathostomin (Nematoda: Cyathostominae) using the nematophagous fungus Duddingtonia flagrans in tropical southeastern Brazil," Veterinary Parasitology, vol. 163, no. 4, pp. 335-340, 2009.

[2] F. R. Braga, J. V. Araújo, A. K. Campos et al., "In vitro evaluation of the action of the nematophagous fungi Duddingtonia flagrans, Monacrosporium sinense and Pochonia chlamydosporia on Fasciola hepatica eggs," World Journal of Microbiology and Biotechnology, vol. 24, no. 8, pp. 1559-1564, 2008.

[3] R. C. L. Assis, A Viabilidade dos fungos predadores Monacrosporium thaumasiume Duddingtonia flagrans $e$ Moxidectina sobre nematoides gastrintestinais de bovinos de corte [Tese de Doutorado], UFV, Viçosa, Brazil, 2013.

[4] R. O. Carvalho, J. V. Araújo, F. R. Braga et al., "Biological control of Ancylostomosis in dogs using the nematode-trapping fungus Monacrosporium thaumasium in southeastern Brazil," Veterinary Parasitology, vol. 165, no. 1-2, pp. 179-183, 2009.

[5] J. V. Araújo, A. P. S. Gomes, and M. P. Guimarães, "Biological control of bovine gastrointestinal nematode parasites in southern Brazil by the nematode-trapping fungus Arthrobotrys robusta," Revista Brasileira de Parasitologia Veterinária, vol. 7, pp. 117-122, 1998.

[6] M. Larsen, P. Nansen, J. Wolstrup, J. Grønvold, S. A. Henriksen, and A. Zorn, "Biological control of trichostrongyles in calves by the fungus Duddingtonia flagrans fed to animals under natural grazing conditions," Veterinary Parasitology, vol. 60, no. 3-4, pp. 321-330, 1995.

[7] A. S. Dias, J. V. Araújo, A. K. Campos, F. R. Braga, and T. A. Fonseca, "Application of a formulation of the nematophagous fungus Duddingtonia flagrans in the control of cattle gastrointestinal nematodiosis," World Journal of Microbiology and Biotechnology, vol. 23, no. 9, pp. 1245-1252, 2007.

[8] J. V. Araújo and W. M. Sampaio, "Effects of temperature, mineral salt and passage through gastrointestinal tract of calves on alginate formulation of Arthrobotrys robusta," Revista Brasileira de Parasitologia Veterinária, vol. 9, pp. 55-59, 2000.

[9] P. Alves, J. Araújo, M. Guimarães, R. L. Assis, P. Sarti, and A. Campos, "Aplicação de formulação do fungo predador de nematóides Monacrosporium thaumasium (Drechsler, 1937) no controle de nematóides de bovinos," Arquivo Brasileiro de Medicina Veterinária e Zootecnia, vol. 55, no. 5, pp. 568-573, 2003.

[10] J. V. Araújo, M. P. Guimarães, A. K. Campos, N. C. Sá, P. Sarti, and R. C. Assis, "Control of bovine gastrointestinal nematode parasites using pellets of the nematode-trapping fungus Monacrosporium thaumasium," Ciência Rural, vol. 34, no. 2, pp. 457-463, 2004.

[11] P. A. Ferreira, S. Ferraz, E. A. Lopes, and L. G. Freitas, "Parasitismo de ovos de Meloidogyne exigua por fungos nematófagos e estudo da compatibilidade entre os isolados fúngicos," Revista Tropical de Ciências Agrárias e Biologicas, vol. 2, no. 21, 2008.

[12] M. Dalla-Pria and S. Ferraz, "Controle biológico de Meloidogyne incognita por seis espécies de Monacrosporium isoladas ou combinadas com Verticillium chlamydosporium," Fitopatologia Brasileira, vol. 21, pp. 30-34, 1996.

[13] T. de Hollanda Ayupe, T. S. A. Monteiro, F. R. Braga et al., "Assessment of compatibility between the nematophagous fungi Arthrobotrys robusta and Duddingtonia flagrans under laboratory conditions," Revista Iberoamericana de Micología, vol. 33, no. 2, pp. 129-130, 2016.
[14] A. D. O. Tavela, J. V. de Araújo, F. R. Braga et al., "Coadministration of sodium alginate pellets containing the fungi Duddingtonia flagrans and Monacrosporium thaumasium on cyathostomin infective larvae after passing through the gastrointestinal tract of horses," Research in Veterinary Science, vol. 94, no. 3, pp. 568-572, 2013.

[15] H. M. Gordon and H. V. Whitlock, "New technique for counting nematode eggs in sheep faeces," Journal of the CSIR, vol. 12, pp. 50-52, 1939.

[16] R. K. Keith, "The differentiation of the infective larvae of some common nematode parasites of cattle," Australian Journal of Zoology, vol. 1, no. 2, pp. 223-235, 1953.

[17] P. M. De Gives, K. G. Davies, S. J. Clark, and J. M. Behnke, "Predatory behaviour of trapping fungi against srf mutants of Caenorhabditis elegans and different plant and animal parasitic nematodes," Parasitology, vol. 119, no. 1, pp. 95-104, 1999.

[18] S.-O. Dimander, J. Höglund, and P. J. Waller, "Seasonal translation of infective larvae of gastrointestinal nematodes of cattle and the effect of Duddingtonia flagrans: A 3-year plot study," Veterinary Parasitology, vol. 117, no. 1-2, pp. 99-116, 2003.

[19] M. E. Fontenot, J. E. Miller, M. T. Peña, M. Larsen, and A. Gillespie, "Efficiency of feeding Duddingtonia flagrans chlamydospores to grazing ewes on reducing availability of parasitic nematode larvae on pasture," Veterinary Parasitology, vol. 118, no. 3-4, pp. 203-213, 2003.

[20] A. R. Silva, J. V. Araújo, F. R. Braga et al., "Biological control of sheep gastrointestinal nematodiasis in a tropical region of the southeast of Brazil with the nematode predatory fungi Duddingtonia flagrans and Monacrosporium thaumasium," Parasitology Research, vol. 105, no. 6, pp. 1707-1713, 2009.

[21] V. Longo Ribeiro Vilela, T. F. Feitosa, F. R. Braga et al., "Coadministration of nematophagous fungi for biological control over gastrointestinal helminths in sheep in the semiarid region of northeastern Brazil," Veterinary Parasitology, vol. 221, pp. 139143, 2016.

[22] F. R. Braga, A. R. e Silva, J. M. Araújo, R. O. Carvalho, J. V. de Araújo, and L. N. Frassy, "Predatory activity of the nematophagous fungi duddingtonia flagrans, monacrosporium thaumasium and arthrobotrys robusta on strongyloides stercoralis infective larvae," Journal of the Brazilian Society of Tropical Medicine, vol. 43, no. 5, pp. 588-590, 2010.

[23] M. Mota, C. Bevilacqua, and J. V. Araújo, "Atividade predatória dos fungos Arthrobotrys conoides e Monacrosporium thaumasium sobre larvas infectantes de Haemonchus contortus de caprinos," Ciência Animal, vol. 10, pp. 37-41, 2000.

[24] M. Morgan, J. M. Behnke, J. A. Lucas, and J. F. Peberdy, "In vitro assessment of the influence of nutrition, temperature and larval density on trapping of the infective larvae of Heligmosomoides polygyrus by Arthrobotrys oligospora, Duddingtonia flagrans and Monacrosporium megalosporum," Parasitology, vol. 115, no. 3, pp. 303-310, 1997.

[25] A. A. Castro, C. R. C. Oliveira, D. H. S. Anjos et al., "Potencial dos fungos nematófagos Arthrobotrys sp. e Monacrosporium thaumasium para o controle de larvas de ciatostomíneos de equinos (Nematoda: Cyathostominae)," Revista Brasileira de Parasitologia Veterinária, vol. 12, no. 2, pp. 53-57, 2003.

[26] P. Mendoza-de Gives and V. M. Vázquez-Prats, "Reduction of Haemonchus contortus infective larvae by three nematophagous fungi in sheep faecal cultures," Veterinary Parasitology, vol. 55, no. 3, pp. 197-203, 1994. 


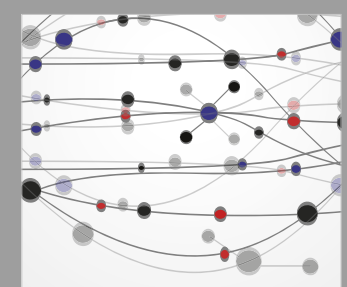

The Scientific World Journal
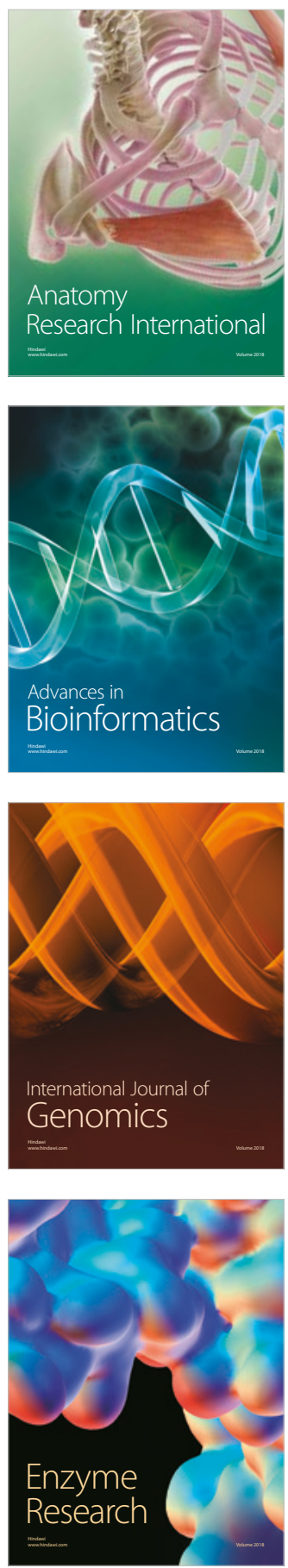
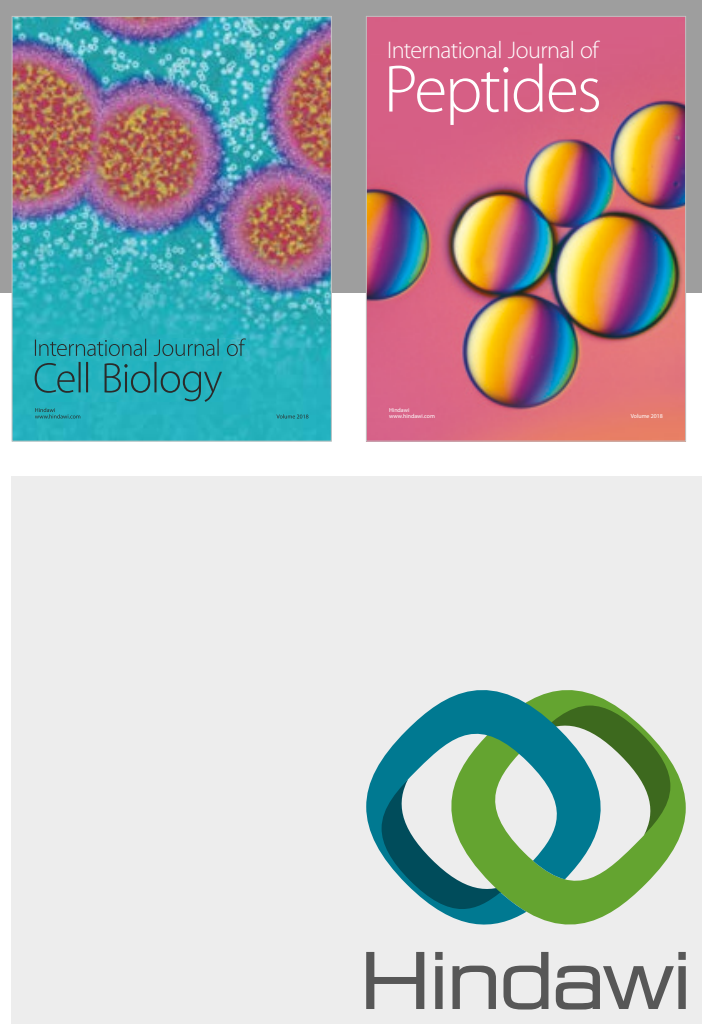

Submit your manuscripts at

www.hindawi.com
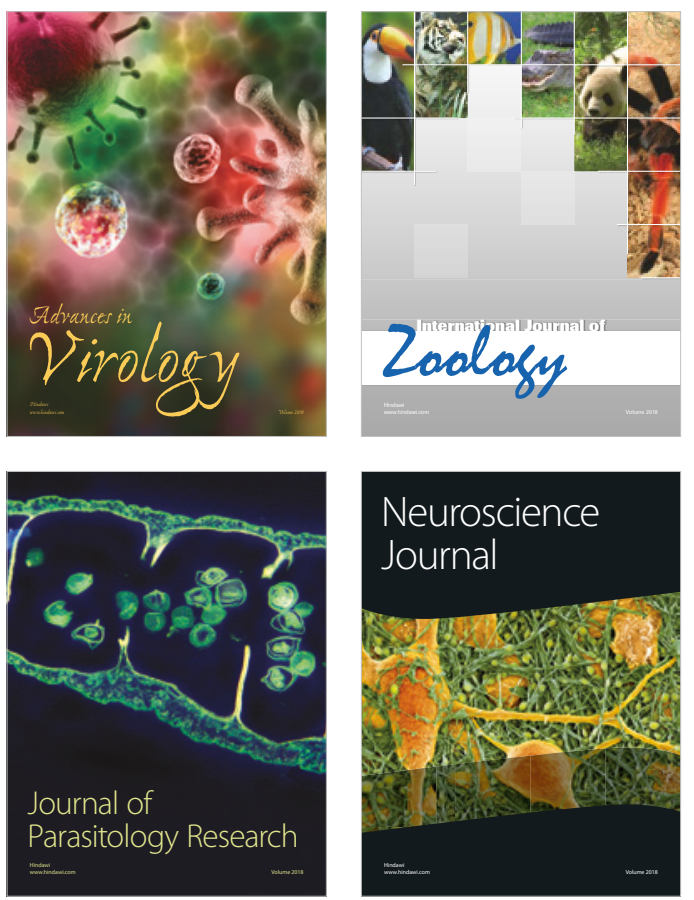
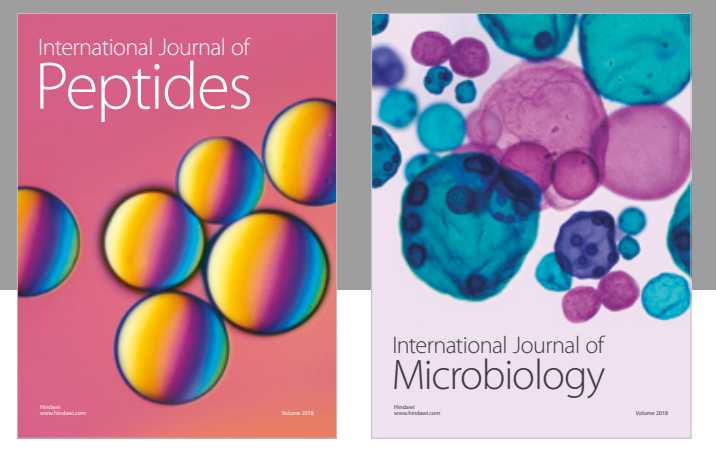

nternational Journal of Microbiology
Journal of
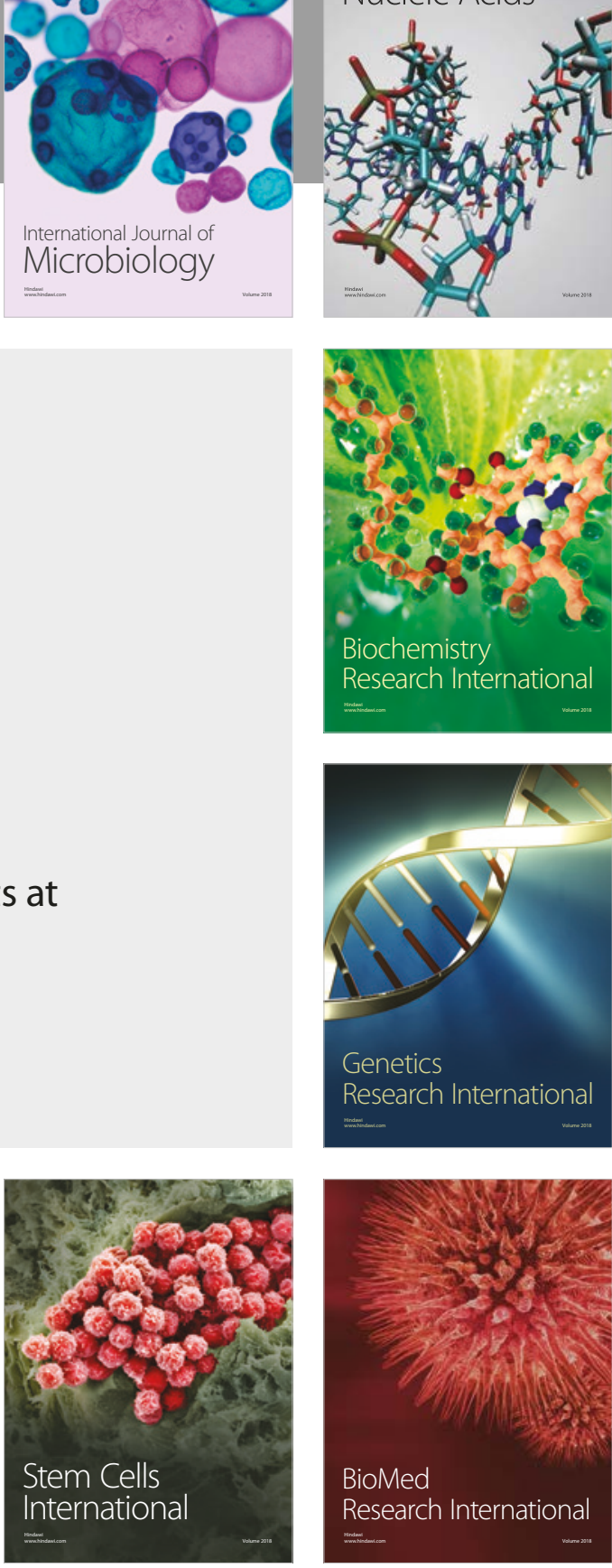
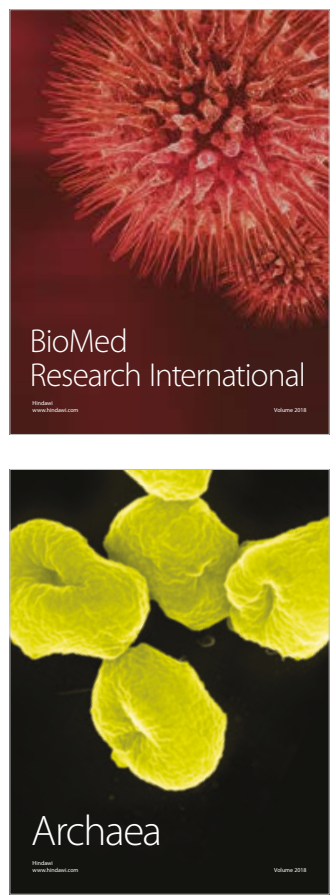